\title{
INFLUÊNCIAS INSTITUCIONAIS OU REGULAÇÃO? UMA ANÁLISE DAS PRÁTICAS DE EVIDENCIAÇÃO OBRIGATÓRIAS DE RECONHECIMENTO DE RECEITAS NO SETOR DE CONSTRUÇÃO EM COMPANHIAS DO BRASIL E INGLATERRA ${ }^{1}$
}

\author{
INSTITUTIONAL INFLUENCES OR REGULATION? AN ANALYSIS OF MANDATORY DISCLO- \\ SURE PRACTICES IN REVENUE RECOGNITION OF CONSTRUCTION COMPANIES FROM \\ BRAZIL AND ENGLAND
}

\author{
Manoel Júnior Ludwig ${ }^{2}$ \\ Bacharel em Ciências Contábeis pela Universidade Federal de Santa Catarina \\ Universidade Federal de Santa Catarina (UFSC) \\ manoel ludwig@hotmail.com \\ https://orcid.org/0000-0003-0944-7047 \\ Rafael Jaime de Souza \\ Bacharel em Ciências Contábeis pela Universidade Federal de Santa Catarina \\ Universidade Federal de Santa Catarina (UFSC) \\ rjaimesouza@hotmail.com \\ https://orcid.org/0000-0002-5580-4941 \\ Alex Mussoi Ribeiro \\ Doutor (USP/SP - controladoria e contabilidade) \\ Universidade Federal de Santa Catarina (UFSC) \\ professoralexmussoi@gmail.com \\ https://orcid.org/0000-0003-3389-9713

\section{Ernesto Fernando Rodrigues Vicente} \\ Doutor em Administração - Universidade de São Paulo \\ Universidade Federal de Santa Catarina (UFSC) \\ ernesto.vicente@ufsc.br \\ https://orcid.org/0000-0002-1992-9982
}

\section{RESUMO}

\footnotetext{
${ }^{1}$ Artigo recebido em: 28/03/2018. Revisado por pares em: 02/05/2018. Reformulado em: 28/07/2018. Recomendado para publicação, após a segunda rodada, em: 21/08/2018 por Luiz Felipe de Araújo Pontes Girão (Editor Geral). Publicado em: 31/08/2018. Organização responsável pelo periódico: UFPB

2 Endereço Campus Universitário, Trindade, Florianópolis - SC, 88040-900 DOI: https://doi.org/10.22478/ufpb.2318-1001.2018v6n3.38962
} 
Objetivo: Investigar se a regulação, traduzida nessa pesquisa pelas normas contábeis e empresas de auditoria, contribuíram para minimizar os efeitos das diferenças institucionais nas políticas contábeis, demonstradas nesse estudo pelo nível de evidenciação do reconhecimento da receita.

Fundamento: As práticas contábeis são influenciadas pelas características institucionais de cada país. Porém, com a convergência internacional das normas contábeis e as Big Four de auditoria atuantes nos dois países, é natural que haja uma harmonização das políticas contábeis, mesmo em países com características institucionais diferentes. Dessa forma, a pesquisa é estruturada sobre os pronunciamentos em relação ao reconhecimento da receita, no setor da construção, emitidos pelo FASB e IASB e nos aspectos teóricos relacionados com o nível de evidenciação.

Método: Foram analisadas, por meio da técnica estatística de dados em painel, as demonstrações contábeis das empresas do Brasil e Inglaterra, do setor de construção, referente aos exercícios findos em 2014, 2015 e 2016. Identificou-se o critério utilizado de reconhecimento de receitas e mensurou-se o nível de evidenciação obrigatória (variável dependente) em função do país sede (variável independente de interesse). Algumas variáveis de controle foram utilizadas: tamanho, rentabilidade, composição acionária e empresa de auditoria.

Resultados: Os resultados indicam que nenhuma variável testada tem poder explicativo sobre o índice de evidenciação e que o nível de evidenciação médio foi de $72,1 \%$ para as empresas de construção da Inglaterra, o qual foi ligeiramente superior ao das empresas brasileiras, na ordem de $70 \%$.

Contribuições: Conclui-se que há indícios de que a regulação exerceu papel de aproximação e equalização, em termos de evidenciação obrigatória, entre os países com diferenças institucionais. Por fim, é possível que as empresas de auditoria tenham papel importante nessa harmonização das práticas contábeis.

Palavras-chave: Reconhecimento da Receita. Evidenciação. Regulação. Diferenças Institucionais. Empresas de Construção.

\section{ABSTRACT}

Objective: The aim of this paper is to investigate whether the regulation, translated in this research by accounting standards and auditing companies, contributed to minimize the effects of institutional differences in accounting policies, showed in this study by the level of disclosure to revenue recognition.

Background: Accounting practices are influenced by the institutional characteristics of each country. However, with the international convergence of accounting standards and Big4 auditing standards in both countries, it is only natural that there is a harmonization of accounting policies, even in countries with different institutional characteristics. Thus, the research is structured in the pronouncements on revenue recognition, in the construction sector, issued by the FASB and IASB and in the theoretical aspects related to the level of disclosure.

Method: The statistical data of the panel data were analyzed by the Brazilian and British companies' financial statements for the years ended in 2014, 2015 and 2016. The criteria used to recognize revenues were identified the level of mandatory disclosure (dependent variable) was measured according to the host country (independent variable of interest). Control variables were used: size, profitability, shareholding composition and audit firm. 
Results: The results indicated that no variable tested has explanatory power on the index of disclosure and that the mean level of disclosure for England, of $72.1 \%$ was slightly higher than that found in Brazilian companies, in the order of $70 \%$.

Contributions: It is concluded that there are indications that regulation exerted a role of approximation and equalization, in terms of mandatory disclosure, between countries with institutional differences. Finally, it is possible for audit firms to play an important role in harmonizing accounting practices.

Keywords: Revenue Recognition. Disclosure. Regulation. Institutional Differences. Construction companies.

\section{INTRODUÇÃO}

É reconhecido que a receita é um dos itens de maior relevância e importância nas demonstrações financeiras (Ciesielski \& Weirich, 2011). No entanto, é uma das questões mais delicadas que os contadores e os legisladores lidam em virtude da sua complexidade, especialmente quando refletem operações de longo prazo (FASB, 2002).

Concomitantemente, a confiabilidade na mensuração da receita se configura como uma das maiores preocupações dos investidores (Anderson \& Yohn, 2002), visto que os gestores podem mascarar ou distorcer os valores (Ciesielski \& Weirich, 2011), tal qual ocorreu em recentes escândalos contábeis, como o caso da Enron (Benston, Bromwich, Litan, \& Wagenhofer, 2003; Dobler, 2008).

Frente ao cenário obscuro de normatização que tange ao assunto e a própria contabilidade em geral, verificou-se a necessidade de harmonizar as normas contábeis em virtude do movimento de globalização do mercado econômico. Assim, em 2001, após uma restruturação do International Accounting Standards Committee (IASC), criou-se o International Accounting Standards Board (IASB), que passou a revisar as International Accounting Standard (IAS) publicadas até então, e a emitir novas normas, em âmbito internacional, conhecidas como as International Financial Reporting Standards (IFRS) (Santos \& Salotti, 2013).

Em termos específicos, o reconhecimento das receitas em empresas de construção é tratado no IAS 11 (Contratos de construção) ou no IAS 18 (Receita), assim como a International Financial Reporting Interpretations Committee (IFRIC) 15, além de recentemente a IFRS 15 que dispõe sobre o tema. É objetivo das normas trazer maior padronização e esclarecimento referente à temática, a fim de promover uma evidenciação dos aspectos relacionados à receita e associados a um maior grau de transparência, confiabilidade e comparabilidade (Mota, Ventura, Silva, \& Paulo, 2015).

Entretanto, o reconhecimento da receita no setor da construção associado ao processo de aderência às normas internacionais, promoveu ampla discussão para os agentes do mercado (profissionais, empresas, auditores e acadêmicos). Há lacunas e possibilidades de incorrer em interpretações díspares, inclusive na utilização de diferentes métodos (Santos \& Salotti, 2013).

Em termos comparativos, desde 2005, a convergência se tornou obrigatória para os países da União Europeia (UE), inclusive o Reino Unido (RU) (Dobler, 2008), que recentemente deixou de integrar a UE. Mais tarde, em 2008, o Brasil também fez adesão às IFRS com a promulgação da Lei n. 11.638, de 2007. (Antunes, Grecco, Formigoni, \& Mendonça, 2012).

Além da questão temporal, há o aspecto institucional de cada país, o qual interfere nas práticas contábeis (Ball, Robin, \& Wu, 2003). Cita-se, por exemplo, como característica institucional o Code Law (Brasil) e Commom Law (Inglaterra) (Ball, Kothari, \& Robin, 2000). Autores como Kvaal e Nobes (2010) defendem que a regulação padronizada não é suficiente para sobressair-se em rela- 
ção às diferenças institucionais, em virtude que as empresas de determinados países carregam algumas práticas observadas pré-IFRS.

Com base neste enfoque, o presente trabalho identificou e discutiu os critérios de reconhecimento de receitas, assim como a sua evidenciação nos relatórios financeiros, de empresas de construção de capital aberto com sede no Brasil e Inglaterra. A comparação entre esses dois países é respaldada pela presença de diferenças institucionais, assim como pela acessibilidade dos dados. Dessa forma, esta pesquisa objetiva investigar se a regulação, traduzida, nesta pesquisa, como as normas contábeis e empresas de auditoria, contribuíram para minimizar os efeitos das diferenças institucionais nas políticas contábeis e, com isto, se aumentou a harmonização das práticas contábeis nas empresas analisadas, demonstradas neste estudo pelo nível de evidenciação do reconhecimento da receita.

A fim de cumprir o presente objetivo, discutiu-se os critérios de reconhecimento de receitas em ambos os países de estudo. Mensurou-se também o nível de evidenciação associado aos itens obrigatórios de divulgação descritos na IAS 11 e IFRIC 15 e, por meio de um modelo de dados em painel, com o acréscimo de variáveis de controle, verificou-se o impacto institucional do país de origem das empresas sobre as práticas de evidenciação entre os anos 2014 a 2016.O período escolhido foi em decorrência de ser o mais recente com dados disponibilizados por todas as companhias e já ter certa distância do processo de convergência inicial (tempo em que as companhias teriam que se adaptar às novas regras).

Esse estudo se justifica pela constante discussão sobre a temática e as respectivas controvérsias ocasionadas pela legislação em relação ao reconhecimento da receita, assim como os seus reflexos na evidenciação, fatores que interferem na qualidade da informação e o seu respectivo uso. Por fim, o estudo é relevante à medida que possibilita compreender se as diferenças institucionais entre os países implicam em alterações no nível de evidenciação obrigatória, assim como o papel da regulação internacional e das empresas de auditoria em termos de harmonização das políticas contábeis.

\section{FUNDAMENTAÇÃO TEÓRICA}

\subsection{Reconhecimento de Receitas e o Aspecto Institucional}

Na linha histórica, os anos 2000 configuraram-se como um novo patamar para a discussão dos critérios para o reconhecimento das receitas. O projeto teve o seu desenvolvimento iniciado pelo $I A S B$, onde o mesmo acredita que essa padronização pode eliminar inconsistências e fraquezas nas normas até então existentes. Por outro lado, o $F A S B$, que também é parte integrante das mudanças, acredita que as alterações são importantes para acompanhar os modelos de negócios atuais (Ciesielski \& Weirich, 2011; Wustemann \& Kierzek, 2005).

Nesta linha, no estudo de Horton, Macve e Serafeim (2011), comenta-se sobre os papéis desempenhados por cada instituição (IASB e $F A S B)$ e que há discordâncias relevantes de pensamento. Porém, ressalta-se que ambos convergem ao fato de que a padronização irá melhorar nos aspectos da comparabilidade e da simplificação das demonstrações financeiras (Ciesielski \& Weirich, 2011).

Wustemann e Kierzek (2005) acreditam que haviam lacunas e inconsistências relevantes no reconhecimento das receitas. Entretanto, conforme a SEC (2001) não se poderia deixar de almejar um reconhecimento oportuno e fidedigno das receitas, além de uma evidenciação adequada, visto que representam um item significativo para os usuários tomarem as suas decisões, seja pelo aspecto evolutivo de prever tendências e geração de caixa futuro ou para avaliar o desempenho passado. 
Dessa forma, em termos normativos, o arcabouço principal que sustenta o reconhecimento das receitas internacionalmente é tratado no IAS 11 (Contratos de construção) ou no IAS 18 (Receita) (Dobler, 2008). Nos termos das empresas de construção, a IAS 11 requer o reconhecimento das receitas pelo método Percentage of Completation (POC). Por outro lado, no caso da IAS 18, a receita é reconhecida somente na entrega das chaves.

Mais adiante, em 2008, foi emitida a IFRIC 15 a fim de esclarecer dúvidas e delimitar como as entidades deveriam proceder e qual pronunciamento seguir. Um dos pontos de discussão seria a transferência dos riscos e do controle ao comprador/cliente (Mota, Campos, Niyama, \& Paulo, 2012). Em geral, Bohusova (2009) acredita que mesmo com esse arranjo de normas, ainda há casos específicos que não se enquadram devido a sua complexidade. Nesse sentido, na tentativa de criar uma maior padronização, elaborou-se a IFRS 15, que visa alinhar as abordagens e determinações tratadas nas normas anteriores, porém, com aplicação obrigatória prevista para o início de 2018.

Em termos específicos, o IAS 11 define um contrato de construção como "um contrato especificamente negociado para a construção de um ativo ou combinação de ativos que são intimamente relacionados ou interdependentes". No item 25, do IAS, define-se que "o reconhecimento de receitas e despesas por referência ao estágio de conclusão de um contrato é frequentemente referido como o método do percentual de acabamento".

Não é consensual a utilização desse método, devido às especificidades do setor, visto que, por exemplo, podem-se ter contratos indexados (valores variáveis). No Brasil, cita-se que os contratos firmados na planta geralmente são corrigidos pelo Custo Unitário Básico (CUB). Dessa forma, em virtude de o valor global da operação ser estimado, ele deve ser atualizado mensalmente nos relatórios e os efetivos efeitos registrados no reconhecimento da receita (Ciesielski \& Weirich, 2011).

Em geral, Barlev (1995) defendia que o tratamento contábil dependeria se os valores do contrato podem ser estimados de forma confiável. Nessa linha, Dobler (2008) discute a aplicação do valor justo, que pode ser crítico em termos de confiabilidade. Adjacente, Colson et al. (2010) acreditam que o reconhecimento deve estar pautado em um grau relevante de confiabilidade.

Em suma, há dois grandes métodos que se discutem para o setor da construção: considerar a evolução da obra ou reconhecer a receita apenas na entrega das chaves. Dobler (2008) discutiu esses dois métodos em seu trabalho baseados na dicotomia de "receitas x custos". Em termos comparativos, o ZPMM (entrega das chaves) requer reconhecimento da receita quando o contrato for concluído e os riscos e benefícios forem transferidos, enquanto que o SOCM (POC - evolução da obra) se baseia em um princípio de realização mais suave, onde a receita e o lucro surgem ao longo de todo o processo construtivo (Wustemann \& Kierzek, 2005).

Adjacente, em termos ilustrativos, a Áustria e a Alemanha não permitiam a utilização da SOCM (Nobes, 2006). Isso acontecia porque ao confiar em um princípio de realização mais suave, é coerente pensar que se terão informações relevantes, mas potencialmente não confiáveis quando comparado ao ZPMM. Dessa forma, esse último configura-se como um método mais conservador (Dobler, 2008).

Nesse sentido, Ferreira e Theóphilo (2007) aplicaram os dois métodos em um estudo de caso. As diferenças encontradas para um exercício apontam que o método da entrega das chaves proporcionou um lucro de $\mathrm{R} \$ 815.867,28$ enquanto pelo método $P O C$, o lucro apurado seria de $\mathrm{R} \$$ 2.522.967,56. Dessa forma, os meios utilizados para se chegar aos resultados devem ser bem evidenciados nas demonstrações, além de se analisar o retrospecto histórico.

Assim, também há uma linha histórica de adesão às normas e institucionalização. O processo de adoção das normas (IAS e IFRS) pela Inglaterra foi mais rápido, em virtude de estar inserida na comunidade europeia, visto que ela foi pioneira na adoção das normas do IASB. Em contraponto, o Brasil se inseriu mais tarde ao meio da convergência internacional, porém, contribuiu para 
internacionalizar o mercado de capitais do Brasil e aumentar a participação das empresas brasileiras nas operações estrangeiras (Santos \& Salotti, 2013).

No aspecto brasileiro, o início da convergência ocorreu com a publicação da Lei n. 11.638/07 (Antunes et al., 2012). Entretanto, Falcão, Pinto e Niyama (2014) acreditam que o "conjunto atual dos IAS e IFRS não contempla uma solução clara e objetiva para realidade brasileira". Em resumo, o IAS 11 e o IAS 18 se transformaram nos CPC 17 (Contratos de Construção) e CPC 30 (Receitas) respectivamente. Mais adiante, surgiram o ICPC 02 (Contratos de Construção do Setor Imobiliário) o OCPC 04 (Entidade de Incorporação Imobiliária para a contabilização de receitas).

Em termos empíricos, Grimm e Hoag (2011) propuseram um caso educacional em formato de artigo, com o objetivo de proporcionar aos leitores a missão de pesquisar e comparar os critérios para reconhecimento, conforme os padrões adotados pelo US GAAP, IFRS GAAP e o padrão proposto para unificação das duas correntes. Entre as constatações, o US GAAP é mais rígido, no qual prevê a transferência formal do bem para o cliente como condição para o reconhecimento da receita. O IFRS GAAP seria mais próximo de retratar a realidade das empresas, e representa em essência o modelo proposto para unificar os dois em virtude da flexibilidade e da possibilidade de estimativas em bases confiáveis.

O modelo proposto é explicado por Marton e Wagenhofer (2010), o qual é resultado da unificação das ideias do $I A S B$ e $F A S B$ em um padrão único. Em resumo, define-se que um contrato com clientes consiste em obrigações de desempenho e que a receita deve ser reconhecida quando satisfizer tais obrigações. Basicamente, pauta-se no critério fundamental da necessidade da transferência do controle do ativo para o cliente.

Wagenhofer (2014) não é favorável à unificação do método, demonstrada em uma única norma, visto que as empresas se diferem por características econômicas e se perderá utilidade da informação. Em geral, essa nova norma, que teve sua discussão ampliada a partir de 2010, irá substituir o IAS 11, IAS 18 e as interpretações relacionadas. Ela é traduzida pela IFRS 15, a qual prevê aplicação obrigatória a partir de 2018 e que o reconhecimento irá ocorrer quando as obrigações de desempenho forem cumpridas (Mota et al., 2015).

Concomitante, em termos de convergência internacional, há de considerar a força das características institucionais de cada país (Ball et al., 2003), especialmente o fato de que a norma permite a utilização de mais de um método. Aspectos relacionados ao sistema jurídico Code Law e Commom Law (Ball et al., 2000; LaPorta, Silanes, Shleifer, \& Vishny, 1997) e as empresas de auditoria são colocados como características fundamentais. Nesse sentido, é conclusivo que a norma pode ser insuficiente para padronizar as práticas contábeis. Kvaal e Nobes (2010) comprovaram que as características inerentes aos países antes da adoção da IFRS permanecem se prevista certa flexibilidade na norma.

\subsection{Evidenciação}

Nos últimos 20 anos houve mudanças significativas a respeito da contabilização e evidenciação das receitas. Colson et al. (2010), em uma discussão teórica das normas contábeis da American Accounting Association's (AAA), acreditavam que o modelo de reconhecimento de receita deve refletir a posição líquida do contrato, fato que avaliza a utilização do método de percentagem de conclusão.

Ainda, os autores acrescentam que as organizações que acreditam que as demonstrações obrigatórias não retratam com precisão o seu desempenho podem buscar outros métodos de divulgação não auditados e altamente discricionários.

Conforme Ciesielski e Weirich (2011) é importante que sejam divulgadas informações pertinentes sobre o item (receita) mais relevante nas demonstrações contábeis. Nessa linha, as empre- 
sas devem divulgar informações qualitativas e quantitativas em duas grandes áreas: (i) contrato com clientes; (ii) julgamentos significativos e mudanças no julgamento.

Na evidenciação da utilização dos métodos, Dylag e Kucharczyk (2011) analisaram empiricamente o reconhecimento das receitas em 17 empresas polonesas por meio da identificação da utilização do IAS 11 (evolução da obra) ou IAS 18 (entrega das chaves) e verificaram que 12 empresas (67\%) utilizaram do método da entrega das chaves e as demais, o método que considera a evolução da obra. Em geral, havia uma convergência futura para utilização do método da entrega das chaves.

O nível de evidenciação foi discutido isoladamente em alguns trabalhos. Lucena e Sousa (2015) analisaram o nível de aderência aos itens requeridos de divulgação dispostos no CPC 17 das empresas brasileiras do setor de construção civil nos anos de 2009 e 2010. Concluíram que em média, cerca de $90 \%$ dos itens não são atendidos.

Estudos similares de caráter empírico foram realizados anteriormente por Niyama, Cavalcante e Rezende (2010), os quais verificaram que diferentes métodos de reconhecimento causam discrepâncias na evidenciação dos resultados, este resultado é corroborado por Mota et al. (2012).

Entretanto, o nível de evidenciação de itens obrigatórios pode sofrer influência de algumas variáveis. Nesse sentido, Wallace e Naser (1995) investigaram os determinantes relacionados ao tamanho, lucratividade, auditoria e setor das empresas listadas na bolsa de valores de Hong Kong.

Esse estudo foi base para Street e Gray (2002), onde os autores analisaram a conformidade com os requisitos de divulgação de todos os IAS de 279 empresas de 32 países. O índice de evidenciação foi de $73 \%$, no qual, uma das constatações era relacionada às empresas de auditoria, que se Big fiver, influenciaria positivamente nesse índice.

Posteriormente, Akhtaruddin (2005) analisou a divulgação obrigatória de empresas de Bangladesh, as quais, em média, atendem em $44 \%$ os itens obrigatórios, e verificou-se que apenas o tamanho da empresa medido pelas vendas é associado positivamente ao índice de evidenciação.

Cunha (2009) a fim de verificar o impacto na evidenciação contábil, por meio da adesão obrigatória ao $I A S B$, analisou, sob a luz do IAS 16, para o exercício de 2005, o índice de evidenciação das empresas da Bolsa de Madri. O índice médio de evidenciação encontrado foi $52 \%$, o qual a autora acredita ser baixo, mas justificável pelo período de adaptação às normas. Por fim, variáveis como tamanho, rentabilidade e setor foram significantes em seu poder explicativo para as alterações no índice de evidenciação.

Em estudo semelhante, Costa e Oliveira (2015) analisaram o efeito aprendizado em relação ao IAS 16, assim como o reflexo no índice de evidenciação, ao longo de seis anos (2005-2010) em empresas listadas na Bolsa de Lisboa. Na linha temporal, houve aumento de 4 p.p., onde passou de uma evidenciação média de 66\% em 2005 para 70\% em 2010. Os resultados também indicam que o tamanho é fator explicativo para o índice de evidenciação.

Por fim, em estudo mais recente, Silva, Silva e Laurencel (2016) avaliaram o nível de evidenciação das empresas de capital aberto listadas na BMF\&Bovespa, no ano de 2012, em relação ao CPC 27 (Ativo Imobilizado). Em média, as 77 empresas analisadas deixaram de divulgar itens obrigatórios na ordem de $32,9 \%$. Os autores verificaram fatores que poderiam influenciar no nível de evidenciação e se testou hipóteses relacionadas ao porte, presença de ADR, empresa de auditoria e segmento, as quais apresentaram resultados significativos.

\section{PROCEDIMENTOS METODOLÓGICOS}

\subsection{Amostra e coleta de dados}


Com relação à população, buscou-se as empresas de construção listadas nas bolsas de valores de cada país, B3(B3 S.A. - Brasil, Bolsa, Balcão), antiga BMF\&Bovespa, no caso do Brasil e a London Stock Exchange no caso da Inglaterra, que estavam abrangidas pela IAS 11.

Optou-se pelas empresas de construção em virtude das complexas possibilidades de reconhecimento de receita dessas entidades, desde o método pautado na conclusão percentual da obra até o método da entrega das chaves. Ambos os critérios são opostos e igualmente aceitos pelas normas atualmente vigentes. Dessa forma, há uma tendência ainda maior para que fatores institucionais atuem mais intensamente que os fatores regulatórios impostos. Nesse sentido, optou-se pela comparação entre o Brasil e Inglaterra, visto que apresentam características institucionais distintas, como por exemplo, a atuação do Code Law (Brasil) e do Commom Law (Inglaterra), que impacta diretamente em como os atos e fatos contábeis são mensurados e evidenciados.

Para a seleção da amostra no Brasil, verificou-se que as companhias abrangidas são as que atuam no segmento de "Construção Pesada", composto por três empresas, e no segmento de "Edificações", composto por 18 empresas, as quais unificadas totalizam 21 empresas na amostra brasileira, conforme descrito na Tabela 01.

Tabela 01

Empresas brasileiras

\begin{tabular}{ll}
\hline \multicolumn{1}{c}{ Edificações } & \multicolumn{1}{c}{ Construção Pesada } \\
\hline Construtora Adolpho Lindenberg S.A. & Azevedo \& Travassos S.A. \\
Construtora Tenda S.A. & Construtora Lix Da Cunha S.A. \\
Cr2 Empreendimentos Imobiliários S.A. & Mendes Junior Engenharia S.A. \\
Cyrela Brazil Realty S.A. & \\
Direcional Engenharia S.A. & \\
Even Construtora E Incorporadora S.A. & \\
Ez Tec Empreendimentos E Participações S.A. & \\
Gafisa S.A. & \\
Helbor Empreendimentos S.A. & \\
Jhsf Participações S.A. & \\
João Fortes Engenharia S.A & \\
Mrv Engenharia E Participações S.A. & \\
Pdg Realty S.A. & \\
Rodobens Negócios Imobiliários S.A. & \\
Rossi Residencial S.A. & \\
Tecnisa S.A. & \\
Trisul S/A & \\
Viver Incorporadora E Construtora S.A &
\end{tabular}

Com relação às empresas britânicas, foram identificadas 34 empresas que atuam no setor de “construction \& materials. A consulta do subsetor se deu individualmente nos sítios eletrônicos de todas as empresas. Dos dois subsetores, apenas as empresas que pertenciam ao subsetor "Heavy Construction" estão abrangidas pelo estudo em virtude da aplicação da norma e dessa forma, originaram a amostra, formada por 14 empresas britânicas, conforme descrito na Tabela 02.

Tabela 02

Empresas britânicas

\begin{tabular}{lll}
\multicolumn{1}{c}{ Building Materials \& Fixtures } & Heavy Construction \\
\hline Accsys Tech & Ashley House & \\
Alumasc Group & Aukett Swanke & \\
Breedon & Balfour B. \\
Crh & Billington \\
Epwin Grp & Boot $(\mathrm{H})$ \\
\hline
\end{tabular}




\section{Forterra}

Fox Marble

Ibstock

Inspirit Energy

James Halstead

Low \& Bonar

Marshalls

Melrose Ind

Michelmersh

Norcros

Polypipe Group

Sigmaroc
Clarke T.

Costain Grp.

Keller Grp.

Kier Group

Morgn Sindl Grp

Mountfield

Nth.Mid.Cons

Smart(J)

Van Elle

Titon Hldgs.

Tyman

Volution

Para se chegar à amostra final foram excluídas duas empresas, sendo uma empresa de cada país. No caso do Brasil, a companhia excluída, apesar de fazer parte deste segmento, não atuava na área de construção nos períodos de análise. Já para a Inglaterra, uma empresa foi excluída, pois só entrou para o mercado de ações em 26/10/2016 e não havia divulgado nenhum Annual Report nos períodos analisados. Desta forma, a amostra analisada foi composta por 33 empresas, das quais 20 são brasileiras e 13 são britânicas.

\subsection{Mensuração da Evidenciação Obrigatória}

A fim de analisar os dados recentes e possíveis avanços das empresas em estudo, após um período de amadurecimento em relação à convergência e as mudanças impostas pela IAS 11 e a IFRIC 15, buscou-se analisar a evidenciação nos três últimos exercícios, referente aos anos de 2014, 2015 e 2016.

A escolha do período ocorreu em função de analisar o momento pós-amadurecimento quanto às mudanças impostas pela adesão à convergência em que as empresas brasileiras foram submetidas. A convergência brasileira iniciou em 2008, e até 2013 considerou-se como um período de aprendizado das entidades quanto à implementação das novas práticas. Assim, se minimizou possíveis vieses que poderiam surgir em comparação às empresas britânicas, em virtude da utilização das IFRS desde 2005.

Para medir o nível de evidenciação, selecionou-se 10 critérios objetivos apresentados na Tabela 04 durante a discussão dos resultados, onde cada empresa foi pontuada em relação ao atendimento ou não do item. Dessa forma, o índice de evidenciação foi medido pela seguinte fórmula:

Onde:

$$
\mathrm{IE}=(\mathrm{IA}) /(\mathrm{IT}-\mathrm{N} / \mathrm{A})
$$

IE - Índice de Evidenciação

IA - Itens atendidos

IT- Itens totais

N/A - Itens não aplicáveis

Os critérios utilizados foram baseados nas normas pertinentes (IAS 11 e IFRIC 15). Quanto ao processo de coleta destes dados, buscaram-se evidências nas notas explicativas de cada empresa que comprovaram, ou não, a utilização das práticas previstas nas normas. Destaca-se que os dois critérios que se relacionam com a IFRIC 15 não são aplicáveis às empresas britânicas. 


\subsection{Análise Estatística}

Para analisar os dados levantados por esta pesquisa, optou-se por uma abordagem estatística de dados em painel. O modelo teórico proposto levou em consideração a evidenciação obrigatória conforme as normas internacionais IAS 11 e IFRIC 15 e o reflexo da diferença entre o país sede da empresa sobre tais práticas conforme equação:

\section{Evidenciação Obrigatória = f (País Sede; Controles)}

Como o objetivo da pesquisa é verificar o efeito direto das diferenças institucionais entre os países sobre as práticas de disclosure no que diz respeito ao reconhecimento de receitas, foi necessário isolar o efeito de possíveis características das empresas que poderiam afetar esta relação. Para escolher as variáveis de controle, este trabalho utilizou como respaldo a teoria da evidenciação voluntária. Segundo Beyer, Cohen, Lys e Walther (2010), as práticas de evidenciação voluntárias podem ser explicadas por uma série de motivos relacionados com as características dos proprietários, incentivos aos gestores e ambiente macroeconômico.

Nesta pesquisa foram isolados os efeitos macroeconômicos por meio da seleção dos países e de apenas um setor de atividade econômica (construção). Os incentivos dos gestores foram controlados pela concentração do capital e pela firma de auditoria. Já os efeitos proprietários foram controlados por meio de variáveis que representam o custo de exposição da companhia no mercado, como seu tamanho e sua performance. As justificativas destas escolhas estão pautadas nas pesquisas de Archambault e Archambault (2003), Beyer et al. (2010), Diamond (1985), Diamond e Verrecchia (1991), Dye (2001), Raffournier (1995), Verrecchia (2001) e Wallace e Naser (1995). Na Tabela 03 foi feito um resumo das variáveis com a sua forma funcional empregada nesta pesquisa.

Tabela 03

\section{Descrição das variáveis utilizadas na pesquisa}

\begin{tabular}{|c|c|c|}
\hline \multicolumn{3}{|l|}{ Variável Dependente } \\
\hline Variável & Descrição & Operacionalização (Modelo Empírico) \\
\hline Evidenciação (IE) & $\begin{array}{l}\text { Nível de evidenciação medido nos relatórios } \\
\text { anuais das companhias analisadas entre os } \\
\text { anos } 2014 \text { e } 2016\end{array}$ & $\mathrm{IE}=(\mathrm{IA}) /(\mathrm{IT}-\mathrm{N} / \mathrm{A})$ \\
\hline \multicolumn{3}{|c|}{ Variável Independente de Interesse } \\
\hline Variável & Descrição & Operacionalização (Modelo Empírico) \\
\hline País sede (PAIS) & $\begin{array}{l}\text { Variável qualitativa que representa o país da } \\
\text { sede da empresa analisada }\end{array}$ & Variável Dummy. Brasil = 1 e Inglaterra $=0$ \\
\hline \multicolumn{3}{|l|}{ Variáveis de Controle } \\
\hline Variável & Descrição & Operacionalização (Modelo Empírico) \\
\hline Tamanho & $\begin{array}{l}\text { Variável quantitativa que representa o porte da } \\
\text { empresa }\end{array}$ & Ln (Logaritmo Natural) do Total do Ativo \\
\hline Rentabilidade (ROA) & $\begin{array}{l}\text { Variável quantitativa que representa a lucrativi- } \\
\text { dade da empresa }\end{array}$ & ROA (Retorno sobre o Ativo) \\
\hline $\begin{array}{l}\text { Composição Acioná- } \\
\text { ria }(\mathrm{CA})\end{array}$ & $\begin{array}{l}\text { Variável quantitativa que representa a diluição } \\
\text { do capital da empresa }\end{array}$ & $\begin{array}{l}\text { Percentual total de participação dos sócios } \\
\text { que representam isoladamente menos de } \\
5 \% \text { do capital }\end{array}$ \\
\hline $\begin{array}{l}\text { Empresa de Auditoria } \\
\text { ( BIG FOUR) }\end{array}$ & $\begin{array}{c}\text { Variável qualitativa que representa a empresa } \\
\text { responsável pela auditoria nas empresas }\end{array}$ & $\begin{array}{c}\text { Variável Dummy. Big Four = } 1 \text { e Não Big } \\
\text { Four }=0\end{array}$ \\
\hline
\end{tabular}

Segundo Fávero (2015), a técnica estatística de dados em painel verifica o efeito agregado da variação between (entre os indivíduos) e whithin (ao longo do tempo). Neste tipo de modelo é imperativo definir como será a variação do intercepto: fixa ou aleatória. Além disto, é necessário 
definir se é necessário fazer o acompanhamento individual da variação temporal (fixo ou aleatório) ou agregado (pooling).

O primeiro passo para tal definição é verificar a característica dos dados. No modelo de efeitos fixos a variação ao longo do tempo é capturada de modo mais adequado no intercepto e deve ser predominante entre as variáveis para ser utilizado. Como nesta pesquisa existe uma variável PAIS (a principal variável de interesse, inclusive) que não varia ao longo do tempo para os indivíduos, o modelo de efeitos fixos não poderá ser utilizado, pois ele não iria capturar o efeito desta característica no modelo.

A decisão fica então entre capturar os efeitos individuais ou agregados ao longo do tempo. O teste utilizado para isto é o Lagrange Multiplier (LM) de Breusch-Pagan. A hipótese nula do teste LM é de que a variância dos resíduos que refletem as diferenças individuais é igual à zero. Neste caso, se ela for rejeitada, o modelo de efeitos aleatórios é mais adequado do que o pooling. Neste trabalho, a H0 do teste LM foi rejeitada. Assim, direcionou-se o painel utilizado para efeitos aleatórios.

Outro aspecto econométrico que poderia gerar problemas no modelo é o agrupamento de observações em algumas variáveis como País sede. Para contornar o problema foi utilizada a opção com erros padrões robustos clusterizados nos indivíduos na estimação do modelo. Esta opção é similar ao Feasible Generalized Last Square (FGLS) em termos de estimação, porém possui a vantagem de também deixar o modelo mais conservador para heterocedasticidade e autocorrelação de resíduos, que são problemas comumente encontrados em painéis desta natureza.

\section{ANÁLISE DE RESULTADO}

\subsection{Nível de Evidenciação - Análise Descritiva}

Identificaram-se nesse estudo os métodos de reconhecimento da receita conhecidos e utilizados, os quais estão pautados no critério da entrega das chaves ou da evolução da obra, porém, para todas as empresas analisadas neste trabalho, o método adotado é a evolução da obra.

Entretanto, a evidenciação do método não é suficiente para compreensão das operações. É necessário divulgar uma série de itens, tanto para atender a legislação, como para disseminar as informações pertinentes entre os usuários da informação.

Tabela 04

Índice de Evidenciação por item de divulgação

\begin{tabular}{|c|c|c|c|c|c|c|c|c|}
\hline \multirow{2}{*}{ Critério } & \multirow{2}{*}{ Descrição } & \multirow{2}{*}{ Base } & \multicolumn{3}{|c|}{ Brasil } & \multicolumn{3}{|c|}{ Inglaterra } \\
\hline & & & 2014 & 2015 & 2016 & 2014 & 2015 & 2016 \\
\hline 1 & $\begin{array}{l}\text { Divulgação do valor das receitas do } \\
\text { contrato reconhecidas como receita no } \\
\text { período. }\end{array}$ & IAS 11 & $70,0 \%$ & $63,2 \%$ & $63,2 \%$ & $61,5 \%$ & $61,5 \%$ & $61,5 \%$ \\
\hline 2 & $\begin{array}{l}\text { Divulgação dos métodos usados para } \\
\text { determinar as receitas do contrato } \\
\text { reconhecidas no período. }\end{array}$ & IAS 11 & $100,0 \%$ & $100,0 \%$ & $100,0 \%$ & $100,0 \%$ & $100,0 \%$ & $100,0 \%$ \\
\hline 3 & $\begin{array}{l}\text { Divulgação dos métodos usados para } \\
\text { determinar o estágio de conclusão de } \\
\text { contratos em andamento. }\end{array}$ & IAS 11 & $90,0 \%$ & $90,0 \%$ & $90,0 \%$ & $100,0 \%$ & $100,0 \%$ & $100,0 \%$ \\
\hline 4 & $\begin{array}{l}\text { Divulgação para contratos em anda- } \\
\text { mento do valor total dos custos incor- } \\
\text { ridos e dos lucros reconhecidos (me- } \\
\text { nos as perdas reconhecidas) até a data } \\
\text { em questão. }\end{array}$ & IAS 11 & $65,0 \%$ & $65,0 \%$ & $65,0 \%$ & $61,5 \%$ & $61,5 \%$ & $61,5 \%$ \\
\hline
\end{tabular}




\begin{tabular}{|c|c|c|c|c|c|c|c|c|}
\hline 5 & $\begin{array}{l}\text { Divulgação para contratos em anda- } \\
\text { mento do valor de adiantamentos } \\
\text { recebidos. }\end{array}$ & IAS 11 & $80,0 \%$ & $80,0 \%$ & $80,0 \%$ & $53,8 \%$ & $53,8 \%$ & $53,8 \%$ \\
\hline 6 & $\begin{array}{l}\text { Divulgação para contratos em anda- } \\
\text { mento do valor de retenções. }\end{array}$ & IAS 11 & $10,0 \%$ & $10,0 \%$ & $10,0 \%$ & $76,9 \%$ & $76,9 \%$ & $76,9 \%$ \\
\hline 7 & $\begin{array}{l}\text { Apresentação do valor bruto devido } \\
\text { de clientes por obras contratadas } \\
\text { como ativo. }\end{array}$ & IAS 11 & $65,0 \%$ & $65,0 \%$ & $70,0 \%$ & $76,9 \%$ & $76,9 \%$ & $76,9 \%$ \\
\hline 8 & $\begin{array}{l}\text { Apresentação do valor bruto devido a } \\
\text { clientes por obras contratadas como } \\
\text { passivo. }\end{array}$ & IAS 11 & $85,0 \%$ & $84,2 \%$ & $84,2 \%$ & $46,2 \%$ & $46,2 \%$ & $46,2 \%$ \\
\hline 9 & $\begin{array}{c}\text { Os critérios utilizados nos contratos } \\
\text { que atendem a todos os requerimen- } \\
\text { tos do item } 14 \text { do Pronunciamento } \\
\text { Técnico CPC } 30 \text { - Receitas. } \\
\end{array}$ & IFRIC 15 & $81,8 \%$ & $81,8 \%$ & $81,8 \%$ & N/A & N/A & N/A \\
\hline 10 & $\begin{array}{l}\text { O valor da receita proveniente desses } \\
\text { contratos no período. }\end{array}$ & IFRIC 15 & $72,7 \%$ & $63,6 \%$ & $63,6 \%$ & N/A & N/A & N/A \\
\hline
\end{tabular}

Os itens necessários para divulgação foram definidos no IAS 11 (CPC 17) e IFRIC 15 (ICPC 02), e conforme a presença ou não nas notas explicativas chegou-se ao índice de evidenciação, conforme demonstrado na Tabela 04. É possível que algum item não seja divulgado pela sua inexistência, entretanto, não foram encontrados subsídios nas notas explicativas capazes de explicar tal ocorrência.

Entre as implicações dos resultados, apresentar o método de reconhecimento da receita é unanimidade, tanto para as empresas do Brasil, como da Inglaterra, conforme observado pelo índice de evidenciação apurado para o critério 2. Com relação ao estágio de conclusão da obra, há também índices quase unânimes, onde na Inglaterra todas as empresas divulgaram o método empregado, enquanto que no Brasil $90 \%$ das empresas o divulgaram, conforme mencionado no critério 3.

Conforme mencionado anteriormente, nos critérios 9 e 10, com relação à IFRIC 15, todas as empresas inglesas pontuaram como não aplicável, visto que nenhuma delas utiliza o padrão da IAS 18 para reconhecimento das receitas.

Outro dado que requer atenção é quanto à evidenciação dos valores de adiantamentos recebidos (Critério 5) e os valores devidos a clientes por obra contratada como passivo (Critério 8). Em ambos, a evidenciação proporcional das empresas brasileiras representa praticamente o dobro das empresas britânicas. Foi apurado também o índice de evidenciação por empresa, o qual é apresentado por meio da estatística descritiva na Tabela 05.

Tabela 05

Índice de Evidenciação por item de divulgação

\begin{tabular}{lccc|ccc}
\hline & \multicolumn{3}{c|}{} & \multicolumn{3}{c}{ Inglaterra } \\
\hline & $\mathbf{2 0 1 4}$ & $\mathbf{2 0 1 5}$ & $\mathbf{2 0 1 6}$ & $\mathbf{2 0 1 4}$ & $\mathbf{2 0 1 5}$ & $\mathbf{2 0 1 6}$ \\
Média & $70,9 \%$ & $69,3 \%$ & $69,8 \%$ & $72,1 \%$ & $72,1 \%$ & $72,1 \%$ \\
Desvio Padrão & $24,3 \%$ & $24,6 \%$ & $24,6 \%$ & $22,3 \%$ & $22,3 \%$ & $22,3 \%$ \\
Máximo & $90,0 \%$ & $90,0 \%$ & $90,0 \%$ & $100,0 \%$ & $100,0 \%$ & $100,0 \%$ \\
Mínimo & $20,0 \%$ & $20,0 \%$ & $20,0 \%$ & $37,5 \%$ & $37,5 \%$ & $37,5 \%$ \\
\hline
\end{tabular}

Verificam-se, quanto à média, que há uma variação praticamente nula entre os dois países. Quanto ao desvio padrão, observar-se que as empresas britânicas apresentaram resultados um pouco inferiores, que podem mostrar uma padronização levemente maior. No entanto, dado a proximidade dos resultados, esses percentuais podem ser tratados como as médias, ou seja, semelhantes entre os países. 
Das 33 empresas analisadas, apenas 3 atenderam a todos os itens de divulgação, e todas são da Inglaterra. Por outro lado, o menor índice foi apurado para apenas uma empresa do Brasil, que evidenciou apenas $20 \%$ dos itens requeridos no IAS. Neste ponto, o menor índice de uma empresa britânica foi quase o dobro (37,5\% dos itens evidenciados).

\subsection{Análise Qualitativa}

Quanto à abordagem qualitativa, destaca-se a nota explicativa trazida pelas 10 empresas que atendem ao critério 6 (Divulgação para contratos em andamento do valor de retenções) da análise. Exemplifica-se por meio da Figura 01, onde se apresenta a nota explicativa divulgada pela empresa Henry Boot PLC.

\section{Construction contracts}

\begin{tabular}{lrr} 
19. Construction contracts & 2016 & 2015 \\
& $\mathfrak{乏}^{\prime} 000$ & $£^{\prime} 000$ \\
\hline Contracts in progress at 31 December: & & \\
Amounts due from contract customers included in trade receivables & $\mathbf{1 7 , 6 3 8}$ & 2,322 \\
Amounts due to contract customers included in trade payables & $\mathbf{( 4 , 6 5 6 )}$ & $(6,529)$ \\
\hline & $\mathbf{1 2 , 9 8 2}$ & $(4,207)$ \\
\hline Contract costs incurred plus recognised profits less recognised losses to date & $\mathbf{4 9 0 , 6 9 3}$ & 357,110 \\
Less: progress billings & $\mathbf{4 4 7 7 , 7 1 1 )}$ & $(361,317)$ \\
\hline
\end{tabular}

At 31 December 2016, retentions held by customers for contract work amounted to £1,614,000 (2015: £1,947,000). Advances received from customers for contract work amounted to $£ 4,656,000$ (2015: $£ 6,529,000)$.

Figura 01. Contratos de Construção Henry Boot PLC Fonte: Annual Report (Henry Boot PLC, 2016).

Nota-se que, com apenas uma nota explicativa, 4 critérios da evidenciação obrigatória foram atendidos pela companhia. Dessa forma, torna-se evidente o atendimento em relação à disposição das normas para o grupo das 10 empresas que a apresentam.

É importante ressaltar que em relação aos itens mensurados e evidenciados pela empresa Henry Boot, destaca-se que nenhuma empresa brasileira apresentou um demonstrativo nesses moldes. Neste sentido, as empresas brasileiras ainda carecem de amadurecimento, visto que não divulgam nenhuma nota explicativa tão completa, fato que pode comprometer a interpretação da informação.

A fim de trazer um exemplo de divulgação positivo no contexto brasileiro, mostra-se, na Figura 02, a nota explicativa da companhia Rossi Residencial S.A.

a) Resultado de vendas de imóveis a apropriar (consolidado)

\begin{tabular}{lrr} 
& \multicolumn{2}{c}{ Consolidado } \\
\cline { 2 - 3 } & $\mathbf{3 1 / 1 2 / 2 0 1 6}$ & $\mathbf{3 1 / 1 2 / 2 0 1 5}$ \\
\hline Vendas contratadas, líquidas de distratos & 2.308 .929 & 4.371 .527 \\
\hline Receitas brutas apropriadas & $(2.155 .753)$ & $(3.932 .891)$ \\
\hline Receitas com vendas de imóveis a apropriar & $\mathbf{1 5 3 . 1 7 6}$ & $\mathbf{4 3 8 . 6 3 6}$ \\
\hline & & \\
Custos orçados dos imóveis vendidos & 2.821 .591 & 4.493 .366 \\
\hline Custos incorridos apropriados & $(2.711 .309)$ & $(4.179 .385)$ \\
\hline Custos orçados a incorrer & $\mathbf{1 1 0 . 2 8 2}$ & $\mathbf{3 1 3 . 9 8 1}$ \\
\hline Resultados de vendas de imóveis a apropriar & $\mathbf{4 2 . 8 9 4}$ & $\mathbf{1 2 4 . 6 5 5}$ \\
\hline
\end{tabular}

Foi utilizado o método do percentual da evolução da obra com base no custo incorrido/custo orçado (POC), para mensuração dos recebíveis das unidades em construção, demonstrados líquidos dos recebimentos.

Figura 02. Nota Explicativa Rossi Residencial S.A. 
Fonte: Notas Explicativas (Rossi Residencial S.A., 2016)

Conforme apresentado na Figura 02, a referida nota evidencia informações relevantes acerca das receitas reconhecidas e que ainda serão reconhecidas referentes aos imóveis já vendidos, bem como o custo na mesma linha de análise e o consequente resultado da atividade. Anexo às informações numéricas, os gestores apresentam o método utilizado para a valoração dos itens.

Para finalizar, a opção de apresentar a Figura 01 e a Figura 02 tem o objetivo de demostrar que há exemplos, mesmo no Brasil, de divulgações eficientes, cujos modelos poderiam ser seguidos por outras empresas, a fim de facilitar a comunicação com os usuários da informação e de proporcionar um maior alinhamento com as normas contábeis aceitas internacionalmente.

\subsection{Análise Quantitativa}

Inicialmente, evidenciou-se a relação das variáveis entre as entidades (Between) e ao longo do tempo (Within), dentro da mesma entidade, conforme Tabela 06.

Tabela 06

Sumário de estatísticas descritivas

\begin{tabular}{ll|cccc|lr}
\hline & Variável & Média & Desvio Padrão & Min & Max & \multicolumn{1}{c}{ Observações } \\
\hline IE & Overall & 0,708 & 0,231 & 0,2 & 1 & $\mathrm{~N}=$ & 99 \\
& Between & & $\mathbf{0 , 2 3 2}$ & 0,2 & 1 & $\mathrm{n}=$ & 33 \\
& Within & & 0,021 & 0,641 & 0,841 & $\mathrm{~T}=$ & 3 \\
\hline TAMANHO & Overall & 20,388 & 2,202 & 15,073 & 23,491 & $\mathrm{~N}=$ & 99 \\
& Between & & $\mathbf{2 , 1 4 5}$ & 16,125 & 23,262 & $\mathrm{n}=$ & 33 \\
& Within & & 0,584 & 15,815 & 22,693 & $\mathrm{~T}=$ & 39 \\
\hline ROA & Overall & $-0,027$ & 0,179 & $-1,168$ & 0,265 & $\mathrm{~N}=$ & 33 \\
& Between & & $\mathbf{0 , 1 3}$ & $-0,486$ & 0,182 & $\mathrm{n}=$ & 3 \\
\hline & Within & & 0,124 & $-0,709$ & 0,429 & $\mathrm{~T}=$ & 99 \\
& Overall & 0,4854 & 0,271 & 0 & 1 & $\mathrm{~N}=$ & 33 \\
& Between & & $\mathbf{0 , 2 6 3}$ & 0,042 & 1 & $\mathrm{n}=$ & 3 \\
\hline
\end{tabular}

Observou-se que para todas essas variáveis a relação entre os indivíduos (between) foi mais relevante do que a variação ao longo do tempo (within). Nota-se, desta forma, que há pouca variabilidade dos dados dentro da mesma empresa para os anos distintos, enquanto que há uma variação maior quando se analisa uma entidade em relação à outra. Pode-se concluir que as empresas mudam pouco seus padrões estabelecidos ao longo do tempo, fato que reforça a ideia de que o período de aprendizado da norma já foi superado. Na sequência, calculou-se a correlação entre as variáveis, conforme demonstrado na Tabela 07.

Tabela 07

Correlação entre as variáveis da pesquisa

\begin{tabular}{l|cccc}
\hline & IE & TAMANHO & ROA & CA \\
\hline IE & 1,000 & & & \\
TAMANHO & $0,456 *$ & 1,000 & 1,000 & \\
ROA & 0,120 & $-0,036$ & 0,075 & 1,000 \\
CA & 0,139 & $-0,197$ & 0,075 \\
\hline
\end{tabular}

Nesta análise, a única correlação significativa encontrada foi quanto ao nível de evidenciação e o tamanho da empresa (0,456 - nível de significância de 5\%). Assim, ao se considerar essas duas variáveis ao longo do tempo, simultaneamente, pode-se inferir que elas são positivamente relacionadas. Todas as outras correlações foram pouco significativas. Assim, a rentabilidade e a 
composição acionária não estão significativamente correlacionadas com o índice de evidenciação. A Tabela 07 também indica uma baixa probabilidade de problemas com a multicolineariedade no modelo, pois a correlação entre as variáveis independentes foi baixa, conforme os padrões estabelecidos por Fávero (2015). Para concluir a análise, utilizou-se a regressão em painel para verificar o efeito entre as variáveis, conforme demonstrado na Tabela 08.

Tabela 08

\section{Resultados da regressão em painel}

\begin{tabular}{|c|c|c|c|c|c|c|}
\hline Nr. Obs. $(\mathrm{N})$ : & 96 & & & & & \\
\hline Nr. Grupos: & 32 & & & & & \\
\hline R-sqwithin: & 0,0275 & & & & & \\
\hline between: & 0,2055 & & & & Wald chi: & 4,27 \\
\hline overall: & 0,1992 & & & & Prob>chi2: & 0,5116 \\
\hline IE & Coeficiente & Erro Padrão & $\mathrm{Z}$ & $P>|z|$ & \multicolumn{2}{|c|}{ [95\% Intervalo Confiança] } \\
\hline PAIS & $-0,033$ & 0,087 & $-0,38$ & 0,707 & $-0,203$ & 0,137 \\
\hline TAMANHO & 0,005 & 0,006 & 0,92 & 0,359 & $-0,006$ & 0,017 \\
\hline ROA & 0,017 & 0,026 & 0,66 & 0,507 & $-0,034$ & 0,069 \\
\hline CA & 0,046 & 0,077 & 0,60 & 0,548 & $-0,105$ & 0,198 \\
\hline BIG FOUR & 0,032 & 0,032 & 1,01 & 0,313 & $-0,030$ & 0,094 \\
\hline Cons & 0,591 & 0,131 & 4,51 & 0,000 & 0,334 & 0,848 \\
\hline
\end{tabular}

sigma_u 0,1932

sigma_e $\quad 0,0263$

Rho $\quad 0,9819$

Nota. Sig t = bi-caudal. A regressão acima foi estimada com GLS com Erros padrão robustos clusterizados nos indivíduos. A constante absorveu as seguintes categorias para as variáveis dummy: PAIS = Inglaterra, BIG FOUR = não. Ela foi obtida com a seguinte equação:

$$
\mathrm{IE}_{\mathrm{i}, \mathrm{t}}=\beta_{0}+\beta_{1} \mathrm{PAIS}_{\mathrm{i}, \mathrm{t}}+\beta_{\mathrm{n}} \text { variảveis de controle } \mathrm{i}_{\mathrm{i}, \mathrm{t}}+\varepsilon_{\mathrm{i}, \mathrm{t}}
$$

Pode-se observar que os coeficientes $(\beta)$ encontrados para todas as variáveis analisadas apontaram nenhum efeito médio significativo sobre o nível de evidenciação ( $p$-value $>0,05)$. Com isto, pode-se afirmar que as variáveis testadas não afetaram significativamente o índice de evidenciação. Este dado contraria estudos similares feitos, como o de Street e Gray (2002), que encontraram indícios de que as empresas de auditoria responsáveis por auditar as demonstrações contábeis estavam positivamente relacionadas com o nível de evidenciação destas empresas. Outro trabalho em conflito com os resultados alcançados é o de Cunha (2009), que observou significativa relação entre a rentabilidade e o tamanho com o nível de evidenciação ao propor uma regressão linear.

É necessário destacar, por outro lado, que o fato das variáveis de controle não terem sido significativas não tem uma denotação negativa, pelo contrário, já era esperado que as mesmas não possuíssem um efeito relevante, pois esta pesquisa utilizou a evidenciação obrigatória e não voluntária como nas pesquisas citadas anteriormente. A grande maioria dos trabalhos que analisam práticas de evidenciação das empresas utilizam uma escala para informações voluntárias na captura do disclosure (para exemplos ver Beyer et al., 2010).

$\mathrm{Na}$ análise de evidenciação voluntária faz sentido à influência de características intrínsecas e extrínsecas sobre a motivação do gestor divulgar ou não determinada informação. Já na evidenciação obrigatória o principal motivador é a própria norma e a forma como ela é fiscalizada (enforcement). Estes aspectos estão mais relacionados com as características institucionais do que com características particulares dos gestores e este foi o principal aspecto analisado por esta pesquisa. A utilização de variáveis de controle mais relacionadas com a divulgação voluntária foi feita em decorrência da carência de trabalhos que analisaram o disclosure obrigatório e da necessidade de isolar possíveis efeitos indesejáveis sobre a relação principal investigada. De qualquer modo, foi feita 
uma variação do modelo sem os controles e os resultados para a variável PAIS se mantiveram os mesmos. Para melhor compreensão dos resultados, foi feita uma análise da variável evidenciação ao longo do tempo e entre os países.

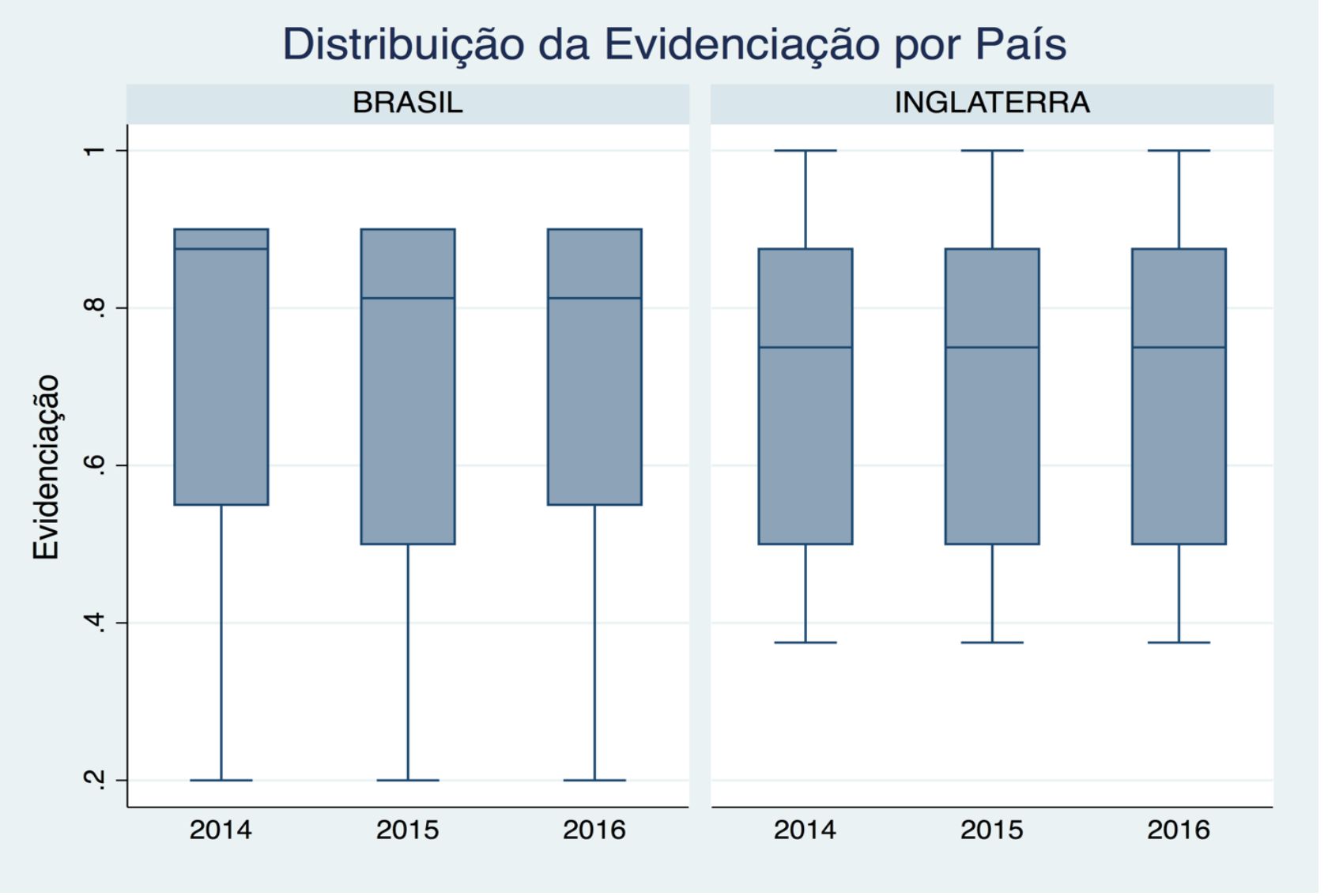

Figura 03. Distribuição da evidenciação por ano e por país

Ao analisar os gráficos de comportamento da variável "nível de evidenciação" ao longo do tempo, percebe-se que em média os níveis dos países são muito próximos para as companhias analisadas. Isto demonstra que a evidenciação se tornou mais homogênea mesmo com características institucionais distintas entre os países.

Os resultados obtidos por esta pesquisa reforçam o papel da regulação como mecanismo de quebra de assimetria entre diferentes ambientes institucionais e destacam (para as companhias analisadas) a relevância de uma norma contábil única para a convergência das práticas contábeis.

Para finalizar, um dos mecanismos necessários para que uma norma seja efetivamente implementada são seus mecanismos fiscalizatórios. Em âmbito privado, as firmas de auditoria possuem um papel relevante neste aspecto, pois elas atestam para o mercado que as companhias seguiram as melhores práticas com base na regulação. Com a adoção das IFRS no Brasil houve um aumento na concentração do mercado de auditoria em torno das chamadas BIG FOUR: PWC, Deloitte, Ernst \& Young e KPMG (Cotrim, Ribeiro, \& Carmo, 2016). Esta maior concentração pode ter facilitado o processo de convergência e harmonização das normas, pois, como são companhias multinacionais, tais firmas de auditoria possuem uma interpretação global e similar aos eventos econômicos mesmo em condições institucionais distintas.

Uma análise temporal da proporção das empresas auditadas por Big Four e o respectivo nível de evidenciação médio (Figura 04) demonstra similaridade entre os países. 


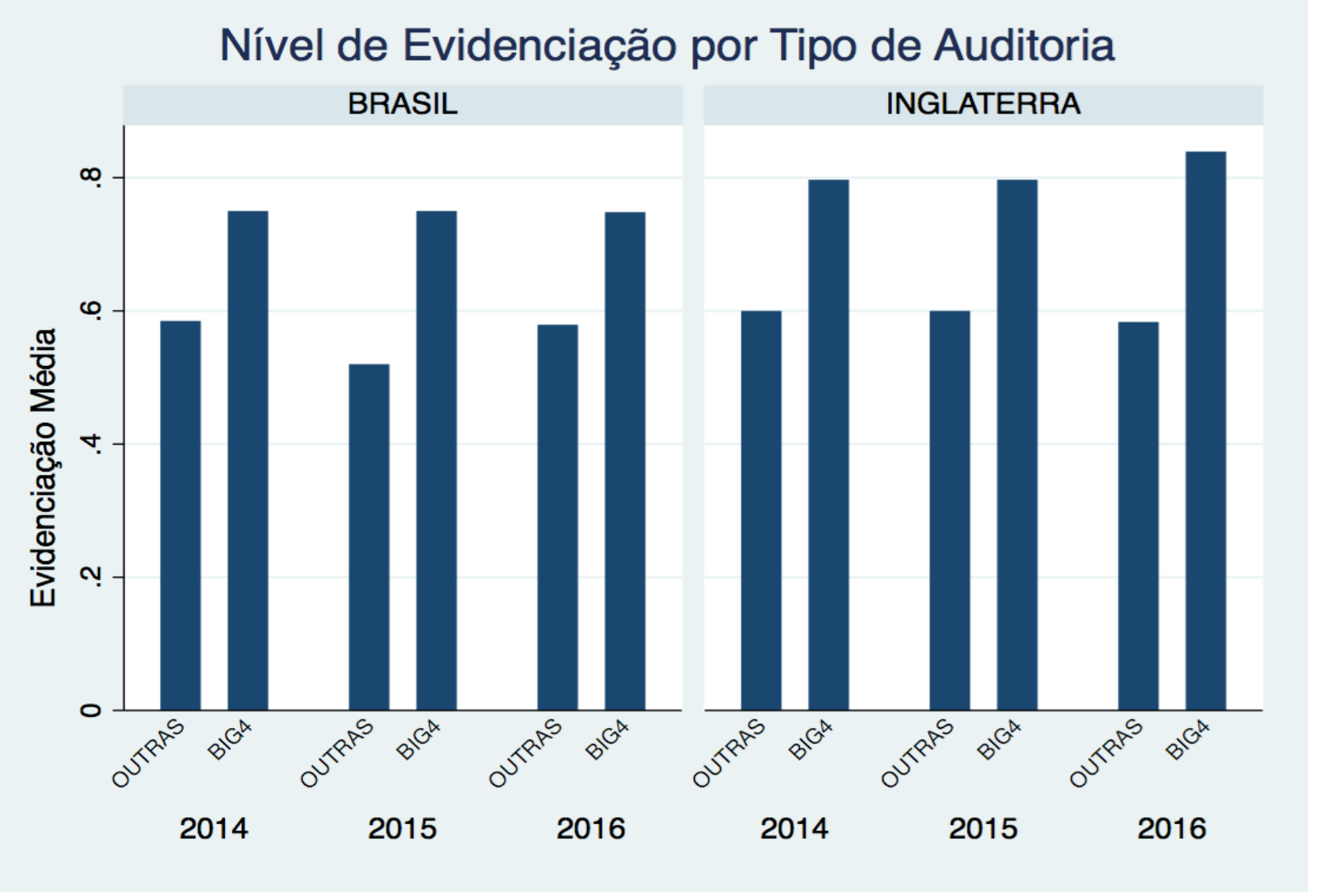

Figura 04. Nível de evidenciação por tipo de auditoria

Nota-se, com base nesta figura, que o nível de evidenciação das empresas auditadas por firmas de auditoria pertencentes ao grupo das Big Four (EY, PwC, Deloitte e KPMG) teve pouca variação ao longo do tempo e é superior aos das companhias não auditadas por uma Big Four. Acrescenta-se que no Brasil 73,33\% dos exercícios foram auditados por empresas Big Four, enquanto que na Inglaterra esse índice foi de aproximadamente 59\%. Em resumo, o fato de a maioria das empresas serem auditadas por Big Four e essas apresentarem um maior nível de evidenciação pode ajudar a explicar a semelhança dos índices de evidenciação apurados das empresas dos dois países.

Em geral, isso acontece porque as empresas de auditoria são reconhecidas, mundialmente, com procedimentos padronizados, independentemente da localidade da empresa. Acrescenta-se também que elas podem fornecer ou forneceram apoio para as empresas brasileiras diminuírem o lastro temporal de adoção das normas em comparação com as empresas britânicas.

\section{CONCLUSÃO}

Este estudo, pautado em dados das empresas de capital aberto do setor de construção do Brasil e Inglaterra, investigou se a regulação contribuiu para minimizar os efeitos das diferenças institucionais nas políticas contábeis, traduzidas nesse estudo, pelo nível de evidenciação do reconhecimento da receita. A fim de concluir sobre, verificou-se os critérios de reconhecimento da receita utilizados, mensurou-se o nível de evidenciação, assim como se testou estatisticamente variáveis relacionadas ao país, tamanho, performance, empresa de auditoria e composição acionária.

Ainda, observou-se a respeito da adesão à norma IFRS 15 (obrigatória a partir de 01/01/2018), que promove ampla discussão no setor da construção, especialmente ao fato de identificar o momento em que ocorre a transferência do controle ao cliente do bem negociado. Nas demonstrações financeiras analisadas, observou-se que nenhuma das empresas se antecipou na utili- 
zação das novas normas, porém, 72\% (10 empresas inglesas e 14 empresas brasileiras) comentam apenas que analisam com frequência os impactos que essa norma pode promover nos demonstrativos e no andamento das operações.

Em termos de evidenciação, observa-se a partir da Tabela 05, que, em termos médios, Inglaterra e Brasil ficaram muito próximos, onde, nos três anos da análise, apurou-se um índice médio de $70 \%$ para as empresas brasileiras e de $72,1 \%$ para as empresas britânicas. Os resultados são próximos, embora com enfoques diferentes, dos encontrados por Silva et al. (2016), que foi de 67,1\% ou Street e Gray (2002), que encontraram em média, 73\% dos itens evidenciados.

Ao que tange em verificar o poder explicativo das variáveis analisadas, ao nível de $5 \%$, não se obteve resultados significativos. Apenas, em termos de correlação, foi possível inferir que o índice de evidenciação e o tamanho correlacionam-se na ordem de 0,456. É possível que os resultados não sejam compatíveis com os encontrados por Silva et al. (2016), que concluíram que quanto maior o porte, maior o nível de evidenciação, visto que o tamanho da amostra ficou restrito a um setor e as variáveis utilizadas estão mais bem explicitadas na teoria da evidenciação voluntária, enquanto nesse estudo o foco foi na evidenciação obrigatória.

Dessa forma, conforme as informações descritas na Tabela 08 concomitante com o nível de evidenciação apresentado na Tabela 05, verifica-se que o nível de evidenciação não sofre interferência do país sede e que, dessa forma, sugere-se que a regulação oriunda do processo de convergência internacional equaliza as diferenças institucionais entre os países objeto do estudo, no período analisado. Essa inferência contradiz grande parte das constatações relacionadas à influência das características institucionais, conforme descrito nos estudos de Ball et al. (2000), Kvaal e Nobes (2010) e LaPorta et al. (1997).

Em resumo, nota-se que mesmo em um cenário de possíveis diferenças institucionais, a adoção da norma (inclusive do mesmo critério de reconhecimento da receita (POC) entre as empresas brasileiras e inglesas) e as práticas de evidenciação convergem. Como possível justificativa para esta aproximação, além da própria regulação, pode-se citar o papel desempenhado pelas empresas de auditoria Big Four, que são globais, auxiliam na disseminação dos padrões contábeis e atuam junto à maioria das empresas analisadas, de ambos os países.

Para pesquisas futuras, sugere-se a abrangência de um maior escopo de amostra de pesquisa ou a utilização de outros países, a fim de aprofundar os estudos em termos de comparabilidade entre países, frente ao processo de convergência internacional. Em âmbito específico, sugere-se, ainda, um comparativo com ambos os países nos moldes de "antes e depois" no que concerne as alterações trazidas pelas normas internacionais, com o intuito de identificar as principais mudanças e os efeitos oriundos da convergência internacional.

\section{REFERÊNCIAS}

Akhtaruddin, M. (2005). Corporate mandatory disclosure practices in Bangladesh. The International Journal of Accounting, 40(4), 399-422.

Anderson, K. L., \& Yohn, T. L. (2002). The effect of 10-K restatements on firm value, information asymmetries, and investors' reliance on earnings [Working paper Georgetown University]. Recuperado de http://dx.doi.org/10.2139/ssrn.332380

Antunes, M. T. R., Grecco, M. C. P., Formigoni, H., \& Mendonça, O. R. de, Neto. (2012). A adoção no Brasil das normas internacionais de contabilidade IFRS: o processo e seus impactos na qualidade da informação contábil. Revista de Economia \& Relações Internacionais, 10(20), 5-19. 
Archambault, J. J., \& Archambault, M. E. (2003). A multinational test of determinants of corporate disclosure. The International Journal of Accounting, 38(2), 173-194.

Ball, R., Kothari, S. P., \& Robin, A. (2000). The -effect of international institutional factors on properties of accounting earnings. Journal of Accounting and Economics, 29(1), 1-51.

Ball, R., Robin, A., \& Wu, J. S. (2003). Incentives versus standards: properties of accounting income in four East Asian countries. Journal of Accounting and Economics, 36(1-3), 235-270.

Barlev, B. (1995). Determining the stage at which it is appropriate to recognise profit under longterm contracts. Journal of Business Finance and Accounting, 22(5), 713-731.

Benston, G., Bromwich, M., Litan, R. E., \& Wagenhofer, A. (2003). Following the Money: the Enron Failure and the State of Corporate Disclosure. Washington, D.C.: AEI-Brookings Joint Center for Regulatory Studies.

Beyer, A., Cohen, D. A., Lys, T. Z., \& Walther, B. R. (2010). The financial reporting environment: Review of the recent literature. Journal of Accounting and Economics, 50(2), 296-343.

Bohusova, H. (2009). Development of the common standard for revenue recording as a part of the US GAAP and IAS/IFRS systems convergence. Rocnik, 57(6), 29-44.

Ciesielski, J. T., \& Weirich, T. R. (2011). Convergence collaboration: revising revenue recognition. Management Accounting Quarterly, 12(3), 18-27.

Colson, R. H., Bloomfield, R., Christensen, T. E., Jamal, K., Moehrle, S., Ohlson, J., . . Watts, R. L. (2010). Response to the Financial Accounting Standards Board's and the International Accounting Standards Board's Joint Discussion Paper Entitled Preliminary Views on Revenue Recognition in Contracts with Customers. Accounting Horizons, 24(4), 689-702.

Costa, F. J. F. da, \& Oliveira, L. C. A. M. de (2015). A divulgação dos ativos fixos tangíveis segundo a IAS 16 e o seu grau de cumprimento. Revista Innovar, 25(spe), 47-60.

Cotrim, V. de S., Ribeiro, A. M., \& Carmo, C. H. S. do (2016, novembro). Efeito das IFRS na concentração do mercado de auditoria: análise com companhias brasileiras de capital aberto. Congresso UNB de Contabilidade e Governança, Brasília, DF, Brasil, 2.

Cunha, P. R. C. M. L. da (2009). O grau de cumprimento com os requisitos previstos na IAS 16: Estudo das empresas cotadas em Espanha (Dissertação de Mestrado). Instituto Universitário de Lisboa IUL, Lisboa, Portugal. Recuperado de https://repositorio.iscte-iul.pt/handle/10071/2485

Diamond, D. W. (1985). Optimal Release of Information By Firms. The Journal of Finance, 40(4), 1071-1094.

Diamond, D. W., \& Verrecchia, R. E. (1991). Disclosure, Liquidity, and the Cost of Capital. The Journal of Finance, 46(4), 1325-1359.

Dobler, M. (2008). Rethinking revenue recognition - the case of construction contracts under International Financial Reporting Standards. J. Revenue Management, 2(1), 1-22. 
Dye, R.A. (2001). An evaluation of "essays on disclosure" and the disclosure literature in accounting. Journal of Accounting and Economics, 32(1-3), 181-235.

Dylag, R., \& Kucharczyk, M. (2011). Recognising revenue from the construction of real estate im financial statements of developers in Poland. Journal of Accounting and Management Information Systems, 10(1), 25-42.

Falcão, D. F., Pinto, L. J. S., \& Niyama, J. K. (2014). Reconhecimento da receita de venda imobiliária: um estudo das maiores S/A's brasileiras no mercado residencial. Revista de Contabilidade do Mestrado em Ciências Contábeis da UERJ, 19(1), 24-41.

FASB (2002). The revenue recognition Project. Acesso em 28-07-17: Recuperado de http://www.gasb.org/cs/BlobServer?blobcol=urldata\&blobtable=MungoBlobs\&blobkey=id\&bl obwhere $=1175818742622 \& b$ blobheader=application $\% 2 F p d f$

Fávero, L. P. (2015). Análise de dados (1a ed.). Rio de Janeiro: Elsevier.

Ferreira, A. R., \& Theóphilo, C. R. (2007). Contabilidade da construção civil: estudo sobre as formas de mensuração e reconhecimento de resultados. Revista de Informação Contábil, 1(1), 49-67.

Grimm, S. D., \& Hoag, D. (2011). Gemini Communications: A case applying revenue recognition standards. Journal of Accounting Education, 29(2-3), 174-190.

Horton, J., Macve, R., \& Serafeim, G. (2011). Deprival value' vs. 'fair value' measurement for contract liabilities: how to resolve the 'revenue recognition' conundrum? Accounting and Business Research, 41(5), 491-514.

IAS 11, December 1993. Construction Contracts. Recuperado de http://www.ifrs.org/issuedstandards/list-of-standards/ias-11-construction-contracts/

IAS 18, December 1993. Revenue. Recuperado de https://www.ifrs.org/issued-standards/list-ofstandards/ias-18-revenue/

IFRIC 15, July 2008. Agreements for the Construction of Real Estate. Recuperado de https://www.ifrs.org/issued-standards/list-of-interpretations/ifric-15-agreements-for-theconstruction-of-real-estate/

Kvaal, E., \& Nobes, C. (2010). International differences in IFRS policy choice: a research note. Accounting and Business Research, 40(2), 173-187.

LaPorta, R., Silanes, F. L. de, Shleifer, A., \& Vishny, R. W. (1997). Legal Determinants of External Finance. The Journal of Finance, 52(3), 1131-1150.

Lucena, W. G. L., \& Sousa, T. C. de M. (2015). Um estudo das empresas listadas na BM\&FBovespa do setor de construção civil acerca do reconhecimento das receitas e dos custos com base no CPC 17. ConTexto, 15(29), 4-16.

Mota, R. H. G., Campos, S. J. de B., Niyama, J. K., \& Paulo, E. (2012). Reconhecimento de receitas nos contratos de construção imobiliária: um estudo do exposure draft ED/2010/6 - receita de contratos com clientes. Revista de Contabilidade do Mestrado em Ciências Contábeis da UERJ, 17(2), 89-103. 
Mota, R. H. G., Ventura, A. F. A., Silva, A. C. da C. e, Filho, \& Paulo, E. (2015). Adoção das normas internacionais de contabilidade: um estudo no setor de construção civil com ações listadas na BM\&FBovespa. Revista Ambiente Contábil, 7(1), 1-17.

Marton, J., \& Wagenhofer, A. (2010). Comment on the IASB Discussion Paper 'Preliminary Views on Revenue Recognition in Contracts with Customers'. Accounting in Europe, 7(1), 3-13.

Niyama, J. K., Cavalcante, P. R. N., \& Rezende, I. C. C. (2010, junho). Normas Contábeis Brasileiras, Norte-americanas e Internacionais aplicáveis ao setor de Construção Civil: uma análise comparativa numa empresa do Estado da Paraíba. Congresso Anpcont, Natal, RN, Brasil, 4.

Nobes, C. W. (2006). Revenue recognition and EU endorsement of IFRS. Accounting in Europe, 3(1), 81-89.

Raffournier, B. (1995). The determinants of voluntary financial disclosure by Swiss listed companies. European Accounting Review, 4(2), 261-280.

Santos, F. B. dos, \& Salotti, B. M. (2013). O método de reconhecimento de receita adotado pelas entidades de incorporação imobiliária brasileiras compromete a comparabilidade das demonstrações financeiras? Revista Contemporânea de Contabilidade, 10(21), 03-24.

SEC (2001) Speech by the SEC staff: revenue recognition. Acesso em 28-07-17. Recuperado dehttps://www.sec.gov/news/speech/spch495.htm

Silva, J. S., Silva, A. H. C. e, \& Laurencel, L. da C. (2016). Nível de evidenciação obrigatória nas empresas de capital aberto: uma análise do CPC 27. Revista Pensar Contábil, 18(65), 40-50.

Street, D. L., \& Gray, S. J. (2002). Factors influencing the extent of corporate compliance with International Accounting Standards: summary of a research monograph. Journal of International Accounting, Auditing \& Taxation, 11(1), 51-76.

Verrecchia, R. E. (2001). Essays on disclosure. Journal of Accounting and Economics, 32(1-3), 97-180.

Wallace, O., \& Naser, K. (1995). Firm-specific determinants of the comprehensiveness of mandatory disclosure in the corporate annual reports of firms listed on the stock exchange of Hong Kong. Journal of Accounting and Public Policy, 14(4), 311-368.

Wagenhofer, A. (2014). The role of revenue recognition in performance reporting. Accounting and Business Research, 44(4), 349-379.

Wustemann, J., \& Kierzek, S. (2005). Revenue recognition under IFRS revisited: conceptual models, current proposals and practical consequences. Accounting in Europe, 2(1), 69-106. 